\title{
NOTAS BIBLJOGRAFICAS
}

Charles R. Wicke: Olmec: An early style in Pre-Columbian Mexico. Tucson, The University of Arizona Press, 1971.

Durante el año de 1965, Charles R. Wicke, antropólogo de la Universidad de las Américas, presentó su tesis doctoral sobre el tema: Lo olmeca, un estilo artístico temprano en el México precolombino. Un libro suyo, con ese mismo título, fue publicado en 1971. El propósito del estudio en él realizado, según lo declara el autor, "ha sido analizar el más temprano de los grandes estilos del México precolombino, el olmeca, con el fin de determinar cómo evolucionó y dónde tuvo su origen" ( $\mathrm{p}, \mathrm{xv}$ ).

En 166 páginas de texto, fotografías y dibujos, Wicke revisa un material que quizá resulta excesivo. Aplica, como aportación personal, métodos que tienden a probar secuencias estilísticas, y considera las influencias y las relaciones existentes entre el arte olmeca y el de otras regiones de Mesoamérica y de Perú.

El primer capítulo del libro trata del aspecto histórico del problema olmeca, a partir del descubrimiento de la Cabeza de Hueyapan en 1862 (Monumento A de Tres Zapotes), y hasta llegar a los inicios de las exploraciones de Michael D. Coe en San Lorenzo, en 1966. Es posible que, durante ese año, Wicke revisara las versión original de su obra, y añadiera información proveniente de los trabajos de Coe.

Quedan fuera de su consideración, por tanto, mucho más de la mitad de las esculturas hoy conocidas en San Lorenzo (los monumentos de San Lorenzo son 65; el primero descubierto por Coe, es el 18) y de La Venta (el personal de la Universidad de California procedió en 1968 a numerar los monumentos; algunos estaban semiperdidos en el Parque-Museo La Venta y en el Museo del Estado, en Villahermosa. La numeración se inició con el Monumento 28, y los monumentos suman un total de 76).

Por esa razón, el estudio de Wicke ha perdido, en buena parte, actualidad, ya que los descubrimientos realizados en los últimos años dentro del campo de la arqueología olmeca, han sido tan continuos como abundantes. Sucede, así, que la cronología utilizada por Wicke para aplicarla a las ciudades olmecas resulta inoperante, pues hoy en día contamos con una serie de fechas más exactamente calculadas.

El segundo capítulo analiza los conceptos de arte y de estilo dentro de un marco de referencia antropológico, y aplica al arte la definición que del estilo formula Kroeber. Según esto, el estilo está compuesto por tres ingredientes:

1. Los temas, que Wicke reduce de manera considerable al afirmar que "seres humanos realistas, jaguares estilizados, más combinaciones infinitamen. te variadas de los dos, componen la mayor parte del tema objetivo olmeca" (p. 68). 
2. El concepto del tema que, de acuerdo con Kroeber, es como el contenido subjetivo subyacente, y es también la forma. Sin embargo, Wicke lo interpreta de manera confusa y personal, pues habla, repitiendo a Kubler, del modo ideográfico o abstracto en los diseños de las máscaras de jaguar, y del modo verosímil o real en las cabezas colosales, así como del propósito de inspirar temor que se manifiesta en cl "principio de frontalidad... expresado en la escultura monumental olmeca" (p. 73).

3. La forma técnica, que para Krocber es la ejecución, la dicción, el ritmo y la pincelada, es para Wicke, en cl arte olmeca, la forma simple, de realismo sensual y ceñido a disciplina arquitectónica: "Arquitectónica es, quizá, la mejor caracterización en una palabra de la forma escultural olmeca" (p. 75).

El capítulo concluye señalando un paralelismo entre arte y lenguaje, que evolucionan siguiendo tendencias o impulsos y pueden ser una sola configuración o dividirse en sus componentes. La transcripción de las definiciones de varios autores -Munro, Panofsky, Krocber y Kluckhohn, Kubler, Forster, Covarrubias y Hansen- le hace posible la aproximación antropológica al arte y al estilo.

El tercer capítulo se ocupa cn ubicar el testimonio arqueológico de acuerdo con diferentes enfoques teóricos que permiten inferencias e interpretaciones distintas. Considera el autor que si confronta teorías de varias disciplinas cuyo objeto común es el estudio del comportamiento del hombre, a saber la etrología, la arqueología, la sociología, la economía y la psicología, podrá ver a los creadores del arte olmeca en diversos contextos, y estará en posibilidad de establecer comparaciones de rasgos culturales.

I as teorías sociológicas de Sorokin y las sociopsicológicas de Fischer concuerdan cuando se aplican al problema de la sociedad olmeca. Estilísticamente, los monolitos olmecas se sitúan dentro del arte idealista, no individualista y colectivista de Sorokin, comparable al concepto igualitario de Fischer. Ambas teorías señalan en el estilo olmeca un elemento jerárquico, relacionable a la vez. con el punto de vista marxista que sostiene que el estilo artístico refleja los intereses de la clase dominante. La información arqueológica muestra a La Venta como un centro ceremonial rodeado de caseríos campesinos, según la clasificación de culturas enunciada por Beardsley; el mismo sitio se integra a la categoría de "núcleo simple diferencialmente centrado", con un "jefe" de la comunidad, y encuentra su paralelo etnográfico en el concepto de la configuración social "Jefatura" de Kaplan. Este mismo autor asienta que el hablar de estado coercitivo al tratar de las antiguas ciudades de Mesoamérica, es resultado de la influencia de la historia reciente, donde predominan la coerción y la religión secular; pero que la integridad de la "Jefatura" se debió a creencias religiosas. Del contenido del arte olmeca se deduce "una religión que se centra en torno al culto a los antepasados y al tótem jaguar" (p. 107), el animal que podía ser la contraparte del líder supremo a quien, conforme a Durkheim, se rendía culto ancestral. En fin, Wicke, de todas las posiciones que revisa, desprende dos aspectos: 1. "Que los principales determinantes del contenido del arte olmeca, son socioculturales; específicamente, la creencia en ascendientes reverenciados y sus cspíritus guardianes 
jaguares", y 2. "Que el determinante psicológico lleva a ciertos aspectos de los temas principales, como el aislamiento de figuras humanas dentro de un nicho, o la elaboración de las bocas en las representaciones de jaguares" (p. 109). "El factor sociocultural es la contribución de una sociedad particular con una cultura específica; el psicológico, la del artista individual" (p. 110).

Todas las especulaciones que Wicke realiza, son antecedentes de la parte medular de su investigación: el factor cstilístico no puede desligarse del cultural y el psicológico, pero puede aislarse con el fin de estudiar los cambios artísticos. Existe la posibilidad de registrar estos cambios en series adecuadas, que darán como resultado el establecimiento de una sccuencia cronológica.

Wicke escoge la Escala de Guttman, que combina datos cualitativos y cuantitativos, y la aplica para fijar el orden temporal en objetos del mismo tipo: a saber, diez cabezas colosales y dieciocho hachas votivas. De conformidad con el escalograma, las cabezas colosales más antiguas son las de San Lorenzo, siguen las de La Vcnta y, finalmente, las de Tres Zapotes. Representan a jefes supremos, por lo cual es inferible que el poder político pasó consecutivamente de uno de esos sitios al otro en el orden mencionado.

En cuanto se refiere a la secuencia de las hachas votivas, muestra que, de diseños simples de motivos felinos, se llega a confimaciones complejas. Una de las hachas más tempranas en la sccucncia llamada Ekholm según Wicke, procede, si se atiende a la información verbal del arqueólogo José Luis Franco, de la Mixteca Alta de Oaxaca; en esta región se encuentra in monolito, el ídolo de San Martín Huamelulpan, cuyos rasgos son semejantes a los que se ven en el hacha en cuestión. Basándose en esta circumstancia, Wicke asevera: "Esta es la razón para concluir que el estilo olmeca florcció primero en la Mixteca Alta" (p. 147).

La última parte del libro se dedica a reconsiderar el problema olmeca $y$ las influencias quc ejerció en el arte maya y en el de Veracruz, y sus relaciones con Guerrero, Monte Albán y el estilo Chavin de Perú.

Wicke da por hccho que fue capaz de "dar una respuesta al hasta aquí insoluble problema de los orígenes olmecas" (p. 162); pero dice dejar sin resolver otros enigmas como el del lapso transcurrido entre cl monolito de Huamelulpan - $j_{\mathrm{cl}}$ primcr monolito olmeca, nada menos!-, quc acusa gran simplicidad, y la compleja escultura de la costa del Golfo.

En cuanto al estilo olmeca, dado que se funde con los estilos clásicos, "no muere de ninguna manera" (p. 162), aun cuando la Estela C de Tres Zapotes se le aparece como cl monumento clave para entender "el fallecimiento de los olmecas" (p. 163), al presentar una máscara felina más evolucionada que las de las hachas votivas y semejante a las de la pirámide E VII sub de Uaxactún.

El arte olmeca, resume Wicke con gran sencillez, nos remite a la organización sociopolítica de sus creadores; se trata de un gobierno de jefes sacerdotes con poder teocrático, que alcanzaba desde Veracruz hasta Guatemala y El Salvador. "La unidad estilística olmeca de Mesoamérica en los tiempos preclásicos, es dcfinitiva" (p. 166). 
Es, para mí, una postura inaceptable el pretender reconstruir toda una cultura, o incluso sus aspectos económicos, sociales y políticos, teniendo como apoyo úmico las obras de arte, cuyo lenguaje sólo en parte nos es comprensible.

No me cabe duda de la erudición de Wicke, pero lamento que en su estuclio la vierta sin obtener de ella frutos mayores. Su deseo de probar con un método cicntífico la evolución estilística de dos conjuntos de obras de arte, resulta incsperada y definitivamente objctable, cuando pretende sustentar la hipótesis acerca del origen de los olmecas, en una arbitraria y nada cientifica suposición accrca de un hacha, de la cual se dicc que proviene de la Mixteca Alta de Oaxaca.

Por lo demás, creo, $y$ así lo he dicho en otras ocasiones, que las cuali. dades objetivas de las obras de arte pueden scr clasificables y mensurables; pero también afirmo que el producto artístico, cn tanto que lo es de un quehacer humano, cs irreductible a una mera fórmula.

B. de la F.

Francis Robicsck: Copán Home of the Mayan Gods. Nucva York, The Museum of the $\Lambda$ merican Indian-I leye Foundation, 1972.

El conocimicnto del arte y la cultura maya está vertido en innumerables trabajos especializados cuyo cnfoque es arqueológico, etnológico, linguístico, epigráfico y artístico. Existen también publicaciones importantes que tratan cl problema de la cultura maya on forma general y cubren la totalidad de sus cxpresiones culturales. Otro tipo de estudios son los que incluyen al arte maya dentro de una amplia consideración sobre el arte prehispánico. Pero, cn general, son escasos los estudios monográficos dedicados al análisis exhaustivo y crítico de una ciudad y sus monumentos y que se ocupen de las expresiones artísticas significativas que le son propias. Es por esto que la monografía de reciente aparición sobre Copán, la importante ciudad maya en Honduras, en el cxtremo oriental del Ârea Maya, representa una importante aportación que fija, precisa y define lo que caracterizó a uno de los centros ceremoniales más importantes del periodo Clásico Maya y pone de relieve, a través de la palabra escrita y por las extraordinarias ilustraciones a color y en blanco y negro, mucho de la belleza arquitectónica y escultórica que aún conserva esta legendaria ciudad maya.

Iil autor de la monografía, Francis Robicsek, es investigador asociado del Museum of the American Indian, Heye Foundation, con sede en Nueva York, institución que edita esta monografía. Robicsek es, además, médico cirujano por profesión; su actividad en este campo lo llevó hace años a Honduras; su interés en la arqueología maya lo condujo e impulsó, desde entonces, al estudio de Copán, la ciudad maya que le da lustre al pasado prehispánico de estc país centroamericano. 